\title{
Comparison of Quantity Characteristics and Antioxidant Potentials of Different Tea Extracts for In-flight Beverage
}

\author{
Jae-il Kwon ${ }^{1}$
}

${ }^{1}$ Department of Travel· Airline Master, Yeungnam University College, Daegu 42415, Korea

\begin{abstract}
Tea is a famous non-alcoholic beverage worldwide. Various types of tea are prepared to meet the demand of different people. Among the various tea types, green tea (GTE), black tea (BTE), and Pu-erh tea (PEE) are major ones. The objective of this study was to investigate the physicochemical characteristics and antioxidant potential of three tea extracts to be considered as an in-flight beverage. The $\mathrm{pH}$ (5.62) of GTE was significantly highest whereas the titratable acidity $(0.18 \mathrm{~g} / 100 \mathrm{~mL})$ was significantly highest in BTE. The highest lightness value was found in GTE (87.12) and redness and yellowness in BTE (30.15 and 85.32). The amount of total free amino acid was significantly highest in PEE $(174.52 \mu \mathrm{g} / \mathrm{mL})$, followed by GTE $(31.28 \mu \mathrm{g} / \mathrm{mL})$ and BTE $(24.98 \mu \mathrm{g} / \mathrm{mL})$. Similarly, the antioxidant potential of PEE was significantly high among the three tea extracts. The results indicated that Pu-erh tea could be a good in-flight beverage.
\end{abstract}

Keywords: Antioxidant Potential, Black Tea, Green Tea, In-flight Beverage, Pu-erh Tea

\section{Introduction}

Tea is one of the most popular drinks in the world. Various types of tea products have been developed and are categorized mainly into six groups (green tea, yellow tea, white tea, oolong tea, black tea, and dark tea) depending upon the processing methods (Hilal 2017). Among them, three tea varieties green, yellow, and white undergo minimal processing, other two oolong tea and black tea are subjected to oxidizing while the other dark tea, such as Pu-erh tea is fermented. There are mainly two methods of Pu-erh preparation: one is by pressing large and unoxidized tea leaves, followed by fermentation for several years at room temperature and the other method is by allowing the tea leaves to ripen for several months using microbes under optimum conditions before being subjected to pressing (Chen et al. 2009). In such ways of processing, Pu-erh tea gets reddish to brownish red or gray appearance, thick and bright red infusion color, bittersweet taste, and a unique moldy odor which becomes more prominent with the fermentation and the leaves aging (Zhou et al. 2004).

The composition of tea is influenced by species, season, age of the leaf (plucking position), climate, and horticultural practices (Lin et al. 1996). Tea products, especially green tea are rich in polyphenols, including flavanols, flavadiols, flavonoids (Hertog et al. 1993), and phenolic acids, accounting for up to $30 \%$ of the dry weight. Another most abundant content of green tea is catechins, which have been known for their hypocholesterolemic effect. Report shows that the long-term feeding of green tea powder to rats could minimize the blood level of triglyceride and other lipids (Lin et al. 1998).

The processing of black tea is characterized by a high degree of fermentation that produces a series of chemical condensations. During the fermentation process, catechins are converted into theaflavins and thearubigins, which are the major black tea polyphenol components (Lin and Liang 2000). Theaflavins possess several health benefits, including fat-reducing and glucose-lowering capabilities and lifestyle-related disease prevention related to antiobesity, anticancer, anti-atherosclerotic, antiinflammatory, antiviral, antibacterial, antiosteoporotic, and anti-dental caries properties (Takemoto and Takemoto 2018). Thearubigins are reported to have various health roles, including antioxidant, antimutagenic and anticancer properties, along with the ability to reduce inflammation and improve gastrointestinal motility (Jt and Je 2020).

$\mathrm{Pu}$-erh tea has already been established as a favorite drink in China and has gained increasing popularity in Southeast Asian countries, Japan, USA, Britain, and other countries. Pu-erh tea is originally produced in the Yunnan Province of China. It has attracted much attention because of its exceptional flavor and potential health benefits (Ahmed et al. 2010). The multiple health-promoting potentials of Pu-erh tea include anti-oxidative (Fan et al. 2013), antibacterial (Hu et al. 2010), antitumor (Zhao et al. 2011), cholesterol-lowering (Peng et al. 2013), anti-obesity (Oi et al. 2012), and hypoglycemic (Du et al. 2012) activities. $\mathrm{Pu}$-erh tea is also rich in various mineral elements compared with black tea, green tea, Oolong tea, and white tea (McKenzie et al. 2010).

Very few studies have been conducted on the effect of drinking tea at high altitudes such as at high mountains or in-flight. A study conducted at the Mt. Everest base camp showed that drinking tea reduced fatigue and positive effect on mood (Scott et al. 2004). The finding of the present study could be 
useful to serve different types of tea as an in-flight beverage.

\section{Materials and Methods \\ Chemicals and materials}

Folin-Ciocalteu phenol reagent and DPPH were purchased from Sigma-Aldrich (St. Louis, MO, USA). All other reagents used were analytical grade. Three commercial tea samples (green tea, black tea, and $\mathrm{Pu}$-erh tea) were purchased from a local market in Deagu, Korea.

\section{Preparation of tea extracts}

Three kinds of tea extracts were prepared with three tea samples and were named as follows: GTE, $1.5 \mathrm{~g}$ of dried green tea was extracted with $150 \mathrm{~mL}$ of boiling water and incubated at $90^{\circ} \mathrm{C}$ for 3 min with shaking for $30 \mathrm{~s}$; BTE, $1.5 \mathrm{~g}$ of dried black tea was extracted with $150 \mathrm{~mL}$ of boiling water and incubated at $90^{\circ} \mathrm{C}$ for 3 min with shaking for $30 \mathrm{~s}$; PEE, $1.5 \mathrm{~g}$ of dried Pu-erh tea was extracted with 150 $\mathrm{mL}$ of boiling water and incubated at $90^{\circ} \mathrm{C}$ for $3 \mathrm{~min}$ with shaking for $30 \mathrm{~s}$. The extraction conditions were designed to get a close similarity to an actual tea brewing (Choi et al. 2018).

\section{Determination of $\mathbf{p H}$ and titratable acidity}

A pH Meter (Model 250; Beckman Coulter, Inc., Fullerton, CA, USA) was used to measure the $\mathrm{pH}$ value of tea extracts. Titratable acidity (lactic acid in $\mathrm{g} / \mathrm{L}$ ) was measured by mixing $5 \mathrm{~mL}$ of the extracts and $125 \mathrm{~mL}$ of deionized water followed by titration with $0.1 \mathrm{~N}$ sodium hydroxide to an endpoint $\mathrm{pH}$ of 8.2 .

\section{Color measurement}

The $\mathrm{L}^{*}$ (lightness), $\mathrm{a}^{*}$ (redness, + or greenness, - ), and $b^{*}$ (yellowness, + or blueness, - ) values of the extracts were determined using a Chroma Meter (CR-300; Minolta Corp., Osaka, Japan). A Minolta calibration plate (YCIE $=94.5, \quad \mathrm{XCIE}=0.3160$, YCIE $=0.330$ ) and a Hunter Lab standard plate $\left(\mathrm{L}^{*}=97.51, \mathrm{a}^{*}=-0.18, \mathrm{~b}^{*}=+1.67\right)$ were used to standardize the instrument using a D65 illuminant as described earlier (Kim et al. 2014).

\section{DPPH radical scavenging activity}

The DPPH radical scavenging activity was measured according to the methods described earlier (Dhungana et al. 2019) with some modifications. A $0.8-\mathrm{mL}$ of $0.2 \mathrm{mM}$ ethanolic solution of DPPH was mixed with $0.2 \mathrm{~mL}$ of the tea extracts. The mixture was thoroughly mixed using a vortexer and left to stand for $30 \mathrm{~min}$ at room temperature under dark conditions, and then the absorbance value was measured at $517 \mathrm{~nm}$ using a microplate spectrophotometer (Multiskan GO, Thermo Fisher Scientific, Vantaa, Finland).

\section{Determination of the total polyphenol content}

The total polyphenol contents of tea extracts were estimated according to the Folin-Ciocalteau method (Dhungana et al. 2016) with some modifications. Fifty microliters of the sample extracts and $1 \mathrm{~mL}$ of $2 \%$ (w/v) aqueous $\mathrm{Na}_{2} \mathrm{CO}_{3}$ were mixed in microtubes and allowed to react at room temperature for $3 \mathrm{~min}$. After $3 \mathrm{~min}$, fifty microliters of $1 \mathrm{~N}$ Folin-Ciocalteau reagent was mixed into the mixture and incubated at room temperature for $30 \mathrm{~min}$ under dark conditions. The absorbance value of the reaction mixtures was measured at $750 \mathrm{~nm}$ using a microplate spectrophotometer (Multiskan GO; Thermo Fisher Scientific). The total polyphenol content of the samples was calculated using the calibration curve drawn using gallic acid (GA) as standard.

\section{Free amino acid composition}

The free amino acid content of tea extracts was determined following a procedure described earlier (Je et al. 2005). An aliquot of the tea extract (1 mL) was hydrolyzed with $6 \mathrm{~N} \mathrm{HCl}(10 \mathrm{~mL})$ in a sealedvacuum ampoule at $110^{\circ} \mathrm{C}$ for $24 \mathrm{~h}$. The $\mathrm{HC} 1$ was removed from the hydrolyzed sample using a rotary evaporator and a known volume $(5 \mathrm{~mL})$ of the reaction mixture was prepared with $0.2 \mathrm{M}$ sodium citrate buffer $(\mathrm{pH}$ 2.2). The mixture was passed through a Sep-Pak C18 cartridge (Waters Co., Milford, MA, USA) and filtered through a $0.22-\mu \mathrm{m}$ membrane filter (Millipore, Billerica, MA, USA). The amino acid profile was determined using an automatic amino acid analyzer (Biochrom-20, Pharmacia Biotech Co., Stockholm, Sweden). All of the samples were run in duplicate and expressed as $\mu \mathrm{g} / \mathrm{mL}$ of tea extract.

\section{Statistical analysis}

All the data were subjected to analysis of variance (ANOVA) using SAS (SAS Institute, Cary, NC, USA). A significant difference between means was determined at $p<0.05$ using Tukey test. A mean value of three replicates was reported unless otherwise stated.

\section{Results and Discussion \\ General chemical characteristics}

The general chemical characteristics of various tea extracts were examined with the $\mathrm{pH}$ and titratable acidity (TA) values. The $\mathrm{pH}$ value of GTE (5.62) was significantly high, followed by PEE (5.55) and BTE (5.21). On the other hand, the TA value was significantly high for BTE $(0.18 \mathrm{~g} / 100 \mathrm{~mL})$ and that of the other two tea samples were statistically equal (Table 1).

The TA value implies an impact of acid content on the flavor of food, whereas that of the $\mathrm{pH}$ indicates an environment that affects the ability of a microorganism to grow in a specific food (Je et al. 
2005). Therefore, the variation in $\mathrm{pH}$ of tea extracts may influence their flavor and shelf-life (Tyl and Sadler 2017). An inverse correlation of $\mathrm{pH}$ and TA might be due to complex acid chemistry in tea extracts, suggesting many acids which exist at an extraction temperature are not (fully) deprotonated at the $\mathrm{pH}$ of the extract, and thus do not contribute to the extract's $\mathrm{pH}$ value, but are measured during titration with a base (Gloess et al. 2013).

Table 1. $\mathrm{pH}$ and titratable acidity of green tea, black tea, and $\mathrm{Pu}$-erh tea extracts

\begin{tabular}{|c|c|c|c|}
\hline & \multicolumn{3}{|l|}{ Sample $^{1)}$} \\
\hline & GTE & BTE & PEE \\
\hline $\mathrm{PH}$ & $5.62 \pm 0.01^{\left.\mathrm{a}^{2}\right)}$ & $5.21 \pm 0.01^{\mathrm{c}}$ & $5.55 \pm 0.02^{b}$ \\
\hline $\begin{array}{l}\text { titratable acidity } \\
(\mathrm{g} / 100 \mathrm{ml})\end{array}$ & $0.12 \pm 0.02^{\mathrm{b}}$ & $0.18 \pm 0.01^{\mathrm{a}}$ & $0.13 \pm 0.01^{\mathrm{b}}$ \\
\hline \multicolumn{4}{|c|}{$\begin{array}{l}{ }^{1)} \mathrm{GTE}: 1.5 \mathrm{~g} \text { of dried green tea was extracted with } 150 \mathrm{~mL} \text { of boiling water and incubated at } 90^{\circ} \mathrm{C} \text { for } 3 \text { min with shaking for } 30 \mathrm{~s} \text {; BTE: } 1.5 \\
\mathrm{~g} \text { of dried black tea was extracted with } 150 \mathrm{~mL} \text { of boiling water and incubated at } 90^{\circ} \mathrm{C} \text { for } 3 \text { min with shaking for } 30 \mathrm{~s} ; \mathrm{PEE}: 1.5 \mathrm{~g} \text { of dried } \\
\text { Pu-erh tea was extracted with } 150 \mathrm{~mL} \text { of boiling water and incubated at } 90^{\circ} \mathrm{C} \text { for } 3 \mathrm{~min} \text { with shaking for } 30 \mathrm{~s} \text {. } \\
{ }^{2)} \text { Values are means } \pm \mathrm{SD} \text { of triplicate measurements. Values followed by different superscrpt letters in the same row are significantly } \\
\text { different }(p<0.05) \text {. }\end{array}$} \\
\hline
\end{tabular}

\section{Color measurement}

The type of tea significantly affected Hunter's color values of three tea extracts (Table 2). The lightness value was significantly highest for GTE (87.12), followed by BTE (59.12) and PEE (45.29). The redness value of GTE, BTE, and PEE was -2.62 , 30.15 , and 0.09 , respectively. On the other hand, the highest and lowest yellowness values were measured in BTE (85.32) and PEE (10.11), respectively.
The substantial variation in the color value of tea extracts might be due to the difference in the polyphenol content (Harbowy et al. 1997) of three tea samples. The color of food is a key factor in making decisions by consumers for its acceptability. Consumers also consider the color of food along with its nutritional and functional values.

Table 2. Hunter's color values of green tea, black tea, and Pu-erh tea extracts

\begin{tabular}{|c|c|c|c|}
\hline \multirow[b]{2}{*}{ Sample $^{1)}$} & \multicolumn{3}{|l|}{ Color value $^{2)}$} \\
\hline & $\begin{array}{l}\mathrm{L}^{*} \\
\text { (lightness) }\end{array}$ & $\begin{array}{l}\mathrm{a}^{*} \\
\text { (redness) }\end{array}$ & $\begin{array}{l}\mathrm{b}^{*} \\
\text { (yellowness) }\end{array}$ \\
\hline GTE & $87.12 \pm 0.13^{\mathrm{a} 3)}$ & $-2.62 \pm 0.03^{c}$ & $18.12 \pm 0.34^{\mathrm{b}}$ \\
\hline BTE & $59.12 \pm 0.11^{\mathrm{b}}$ & $30.15 \pm 0.01^{\mathrm{a}}$ & $85.32 \pm 0.31^{\mathrm{a}}$ \\
\hline PEE & $45.29 \pm 0.23^{\mathrm{c}}$ & $0.09 \pm 0.02^{\mathrm{b}}$ & $10.11 \pm 0.05^{\mathrm{c}}$ \\
\hline
\end{tabular}

${ }^{1)}$ Samples are defined in Table 1.

${ }^{2)} \mathrm{L}^{*}$, lightness $\left(100\right.$, white; 0 , black); $\mathrm{a}^{*}$, redness (-, green;,+ red); $\mathrm{b}^{*}$, yellowness $(-$, blue; + , yellow).

${ }^{3)}$ Values are expressed as means \pm standard deviations of three replicates. Values followed by different superscript letters in the same column are significantly different $(p<0.05)$.

\section{Free amino acid composition}

The content of individual free amino acids and their total amount in three tea extracts are shown in Table 3. A total of 19 free amino acids were detected in all three samples and one amino acid L-citrulline was not detected in the samples. Only BTE was found not to contain three amino acids L-histidine, O-phosphoL-serine, and L-ornithine. The highest amount of total free amino acid was found in PEE (174.52 $\mu \mathrm{g} / \mathrm{mL})$, followed by GTE $(31.28 \mu \mathrm{g} / \mathrm{mL})$ and BTE $(24.98 \mu \mathrm{g} / \mathrm{mL})$. L-phenylalanine was the most abundant essential and L-aspartic acid was the most abundant non-essential amino acid detected in the tea extracts. PEE contained the highest amount of all the amino acids.

The amount of amino acids is one of the key factors in determining the nutritional qualities of food materials (Basarova and Janousek 2000). $\gamma$-Amino-nbutyric acid (GABA) is basically synthesized in plant tissues by decarboxylation of glutamic acid in the presence of glutamate decarboxylase (Nikmaram et al. 2017). GABA and glycine are related to learning and memory, stroke, and neurodegenerative diseases; relieving anxiety, sedation, anticonvulsant, and muscle relaxation function (Krogsgaard-Larsen 1989; Mody et al. 1994; Oh and Oh 2004). 


\begin{tabular}{|c|c|c|c|}
\hline \multirow{2}{*}{ Amino acid } & \multicolumn{3}{|c|}{ Sample $^{1)}$} \\
\hline & GTE & BTE & PEE \\
\hline \multicolumn{4}{|l|}{ Essential amino acid } \\
\hline L-Threonine & $0.21^{4}$ & 0.10 & 5.21 \\
\hline L-Valine & 0.27 & 0.22 & 4.22 \\
\hline L-Methionine L-Isoleucine & 0.93 & 0.16 & 2.31 \\
\hline L-Leucine & 1.72 & 0.14 & 3.00 \\
\hline L-Phenylalanine & 1.23 & 0.77 & 7.27 \\
\hline L-Lysine & 0.55 & 1.12 & 2.69 \\
\hline L-Histidine & 0.09 & $\mathrm{ND}^{\prime \prime}$ & 0.12 \\
\hline Sub-total & 5.00 & 2.51 & 24.82 \\
\hline \multicolumn{4}{|l|}{ Non-essential amino acid } \\
\hline L-Aspartic acid & 2.97 & 1.92 & 24.31 \\
\hline L-Serine & 0.27 & 1.21 & 8.12 \\
\hline L-Glutamic acid & 0.71 & 1.71 & 25.37 \\
\hline Glycine & 0.52 & 1.22 & 1.11 \\
\hline L-Alanine & 1.27 & 1.31 & 6.35 \\
\hline L-Tyrosine & 0.49 & 1.44 & 5.13 \\
\hline L-Arginine & 1.77 & 1.51 & 6.23 \\
\hline Sub-total & 8.00 & 10.32 & 76.62 \\
\hline \multicolumn{4}{|l|}{ Other free amino acid } \\
\hline O-Phospho-L-serine & 0.92 & ND & 6.77 \\
\hline O-Phospho ethanol amine & 1.22 & 2.00 & 3.39 \\
\hline L-Sarcosine & 15.77 & 9.99 & 57.22 \\
\hline L-Citrulline & ND & ND & $\mathrm{ND}$ \\
\hline$\beta$-Alanine & 0.09 & 0.02 & 0.22 \\
\hline D,L- $\beta$-Amino isobutyric acid & 0.10 & 0.01 & 1.00 \\
\hline$\gamma$-Amino-n-butyric acid & 0.12 & 0.06 & 1.31 \\
\hline Ethanolamine & 0.02 & 0.07 & 1.60 \\
\hline L-Ornithine & 0.04 & ND & 1.11 \\
\hline Sub-total & 18.28 & 12.15 & 73.08 \\
\hline Total free amino acid & 31.28 & 24.98 & 174.52 \\
\hline
\end{tabular}

\section{Antioxidant potential}

The antioxidant potential of three tea extracts was evaluated by DPPH free radical scavenging activity and total polyphenol content (Table 4). The DPPH radical-scavenging potential of PEE $(88.81 \%)$ was significantly highest among the tea samples. Similarly, the total polyphenol content was highest in PEE (1950.32 $\mu \mathrm{g} \mathrm{GAE} / \mathrm{mL})$ and lowest in PTE (457.23 $\mu \mathrm{g} \mathrm{GAE} / \mathrm{mL}$ ).

A similar result of higher polyphenol content in green tea than in black tea was also found in previous studies (Widowati et al. 2015; Zhao et al. 2019). The lower total polyphenol content of black tea extract might be due to the extended fermentation by polyphenol oxidases (Atoui et al. 2005). In the present study, total polyphenol content was significantly higher in GTE than that in BTE, however, the DPPH was significantly higher in BTE than in GTE. The overall antioxidant potential of a product is a consequence of the interaction of various factors, such as the segregating nature of specific antioxidants, condition of oxidation, and/or physical state of the oxidizable substrate (Frankel and Meyer 2000). Hence, a noticeable rise in the amount of an antioxidant component, such as total polyphenol content, may not always result in elevated antioxidant potentials.

Table 4. DPPH free-radical scavenging activities and total phenol content (TPC) of green tea, black tea, and Pu-erh tea extracts

\begin{tabular}{|c|c|c|}
\hline Sample ${ }^{1)}$ & $\begin{array}{l}\text { DPPH } \\
\text { (\% Inhibition) }\end{array}$ & $\begin{array}{l}\text { TPC } \\
(\mu \mathrm{g} \mathrm{GAE} / 2) / m L \text { tea extract })\end{array}$ \\
\hline GTE & $74.23 \pm 1.11^{\mathrm{c} 3)}$ & $980.31 \pm 7.23^{\mathrm{b}}$ \\
\hline BTE & $80.23 \pm 2.05^{\mathrm{b}}$ & $457.23 \pm 5.34^{\mathrm{c}}$ \\
\hline PEE & $88.81 \pm 1.23^{\mathrm{a}}$ & $1950.32 \pm 6.13^{\mathrm{a}}$ \\
\hline
\end{tabular}

${ }^{\text {I) }}$ Samples are defined in Table 1.

${ }^{2)}$ Gallic acid equivalents.

${ }^{3)}$ Values are means \pm SD of triplicate measurements. The Values followed by different superscript letters in the same column are significantly different $(p<0.05)$. 


\section{Conclusions}

The $\mathrm{pH}$, titratable acidity, color value, free amino acid contents, and antioxidant potential of green tea, black tea, and $\mathrm{Pu}$-erh tea extracts were investigated as a potential in-flight beverage. The free amino acid content and antioxidant potential results showed that $\mathrm{Pu}$-erh tea could be the best tea drink to serve inflight.

\section{References}

1. Ahmed S, Unachukwu U, Stepp JR, et al (2010) Pu-erh tea tasting in Yunnan, China: Correlation of drinkers' perceptions to phytochemistry. J Ethnopharmacol 132:176185. https://doi.org/10.1016/j.jep.2010.08.016

2. Atoui A, Mansouri A, Boskou G, Kefalas P (2005) Tea and herbal infusions: Their antioxidant activity and phenolic profile. Food $\quad$ Chem 89:27-36. https://doi.org/10.1016/j.foodchem.2004.01.075

3. Basarova G, Janousek J (2000) Importance of amino acids in beer technology and quality. Kvasny Prumysl 46:314-318

4. Chen H-Y, Lin-Shiau S-Y, Lin J-K (2009) Pu-erh tea; its manufacturing and health benefits. pp. 9-15. In: Tea and Tea Products: Chemistry and Health-Promoting Properties. Ho C-T, Lin J-K, Shahidi F (ed). CRC Press, Boca Raton, FL, USA.

5. Choi S-H, Kim I-D, Dhungana SK, Kim D-G (2018) Comparison of quality characteristic and antioxidant potential of cultivated Pu-erh and Gushu Pu-erh tea extracts at two temperatures. J Pure Appl Microbiol 12:1155-1161. https://doi.org/10.22207/JPAM.12.3.14

6. Dhungana SK, Kim I-D, Adhikari B, et al (2019) Reduced germination and seedling vigor of weeds with root extracts of maize and soybean, and the mechanism defined as allelopathic. J Crop Sci Biotechnol 22:11-16. https://doi.org/10.1007/s12892-018-0251-0

7. Dhungana SK, Kim I-D, Kwak H-S, Shin D-H (2016) Unraveling the effect of structurally different classes of insecticide on germination and early plant growth of soybean [Glycine max (L.) Merr.]. Pestic Biochem Physiol 130:39-43. https://doi.org/10.1016/j.pestbp.2015.12.002

8. Du W, Peng S-M, Liu Z, et al (2012) Hypoglycemic effect of the water extract of Pu-erh tea. J Agric Food Chem 60:10126-10132. https://doi.org/10.1021/jf302426w

9. Fan JP, Fan C, Dong WM, et al (2013) Free radical scavenging and anti-oxidative activities of an ethanol-soluble pigment extract prepared from fermented Zijuan Pu-erh tea. Food Chem Toxicol 59:527-533. https://doi.org/10.1016/j.fct.2013.06.047

10. Frankel EN, Meyer AS (2000) The problems of using onedimensional methods to evaluate multifunctional food and biological antioxidants. J Sci Food Agric 80:1925-1941. https://doi.org/10.1002/1097-

0010(200010)80:13<1925*:AID-JSFA714>3.0.CO $2-4$

11. Gloess AN, Schönbächler B, Klopprogge B, et al (2013) Comparison of nine common coffee extraction methods: instrumental and sensory analysis. Eur Food Res Technol 236:607-627. https://doi.org/10.1007/s00217-013-1917-x

12. Harbowy ME, Balentine DA, Davies AP, Cai Y (1997) Tea chemistry. Crit Rev Plant Sci 16:415-480. https://doi.org/10.1080/07352689709701956

13. Hertog MGL, Hollman PCH, Katan MB, Kromhout D (1993) Intake of potentially anticarcinogenic flavonoids and their determinants in adults in the Netherlands. Nutr Cancer 20:21-29. https://doi.org/10.1080/01635589309514267

14. Hilal Y (2017) Morphology, manufacturing, types, composition and medicinal properties of tea (Camellia sinensis). J Basic Appl Plant Sci 1:107

15. Hu Y, Jia J, Qiao J, et al (2010) Antimicrobial activity of Puerh tea extracts in vitro and its effects on the preservation of cooled mutton. J Food Saf 30:177-195. https://doi.org/10.1111/j.1745-4565.2009.00199.x

16. Je J-Y, Park P-J, Jung W-K, Kim S-K (2005) Amino acid changes in fermented oyster (Crassostrea gigas) sauce with different fermentation periods. Food Chem 91:15-18. https://doi.org/10.1016/j.foodchem.2004.05.061

17. Jt B, Je D (2020) Black tea flavonoids: A focus on thearubigins and their potential roles in diet \& health. Nutr Food Technol Open Access 6(2). https://doi.org/10.16966/2470-6086.168

18. Kim I-D, Lee J-W, Kim S-J, et al (2014) Exogenous application of natural extracts of persimmon (Diospyros kaki Thunb.) can help in maintaining nutritional and mineral composition of dried persimmon. Afr J Biotechnol 13:22312239. https://doi.org/10.5897/AJB2013.13503

19. Krogsgaard-Larsen P (1989) GABA receptors. In: Receptor Pharmacology and Function. Williams M, Glennon RA, Timmermans PMWM (eds). Marcel Dekker Inc., New York, NY, USA, pp 349-383

20. Lin JK, Liang YC (2000) Cancer chemoprevention by tea polyphenols. Proc Natl Sci Counc Repub China B 24:1-13

21. Lin Y-L, Cheng C-Y, Lin Y-P, et al (1998) Hypolipidemic effect of green tea leaves through induction of antioxidant and phase II enzymes including superoxide dismutase, catalase, and glutathione $S$-transferase in rats. J Agric Food Chem 46:1893-1899. https://doi.org/10.1021/jf970963q

22. Lin Y-L, Juan I-M, Chen Y-L, et al (1996) Composition of polyphenols in fresh tea leaves and associations of their oxygen-radical-absorbing capacity with antiproliferative actions in fibroblast cells. J Agric Food Chem 44:1387-1394. https://doi.org/10.1021/jf950652k

23. McKenzie JS, Jurado JM, de Pablos F (2010) Characterisation of tea leaves according to their total mineral content by means of probabilistic neural networks. Food Chem https://doi.org/10.1016/j.foodchem.2010.05.007

$23: 859-864$.

24. Mody I, De Koninck Y, Otis TS, Soltesz I (1994) Bridging the cleft at GABA synapses in the brain. Trends Neurosci 17:517-525. https://doi.org/10.1016/0166-2236(94)90155-4

25. Nikmaram N, Dar B, Roohinejad S, et al (2017) Recent advances in $\gamma$-aminobutyric acid (GABA) properties in pulses: An overview. J Sci Food Agric 97:2681-2689. https://doi.org/10.1002/jsfa.8283

26. Oh C-H, Oh S-H (2004) Effects of germinated brown rice extracts with enhanced levels of GABA on cancer cell proliferation and apoptosis. J Med Food 7:19-23. https://doi.org/10.1089/109662004322984653

27. Oi Y, Hou I-C, Fujita H, Yazawa K (2012) Antiobesity effects of Chinese black tea (Pu-erh tea) extract and gallic acid. Phytother Res 26:475-481. https://doi.org/10.1002/ptr.3602

28. Peng C, Wang Q, Liu H, et al (2013) Effects of Zijuan pu-erh tea theabrownin on metabolites in hyperlipidemic rat feces by Py-GC/MS. J Anal Appl Pyrolysis 104:226-233. https://doi.org/10.1016/j.jaap.2013.07.011

29. Scott D, Rycroft JA, Aspen J, et al (2004) The effect of drinking tea at high altitude on hydration status and mood. Eur J Appl Physiol 91:493-498. https://doi.org/10.1007/s00421-003-1015-z

30. Takemoto M, Takemoto H (2018) Synthesis of theaflavins and their functions. Molecules 23:918. https://doi.org/10.3390/molecules23040918

31. Tyl C, Sadler GC (2017) pH and titratable acidity. pp. 389406. In: Food Analysis. Nielsen SS (ed). Springer Science, Basel, Switzerland.

32. Widowati W, Herlina T, Ratnawati H, et al (2015) Antioxidant potential of black, green and oolong tea methanol extracts. Biol Med Nat Prod Chem 4:35-39. https://doi.org/10.14421/biomedich.2015.42.35-39

33. Zhao C-N, Tang G-Y, Cao S-Y, et al (2019) Phenolic profiles and antioxidant activities of 30 tea infusions from green, black, oolong, white, yellow and dark teas. Antioxidants 8:215. https://doi.org/10.3390/antiox8070215

34. Zhao L, Jia S, Tang W, et al (2011) Pu-erh tea inhibits tumor cell growth by down-regulating mutant p53. Int J Mol Sci 12:7581-7593. https://doi.org/10.3390/ijms12117581

35. Zhou HJ, Li JH, Zhao FL, Han J, Yang XJ, Yang W, Wu XZ (2004). Study on main microbes on quality formation of Yunnan Pu-erh tea during pile-fermentation process. Journal of Tea Science 24: 212-218 (in Chinese). 